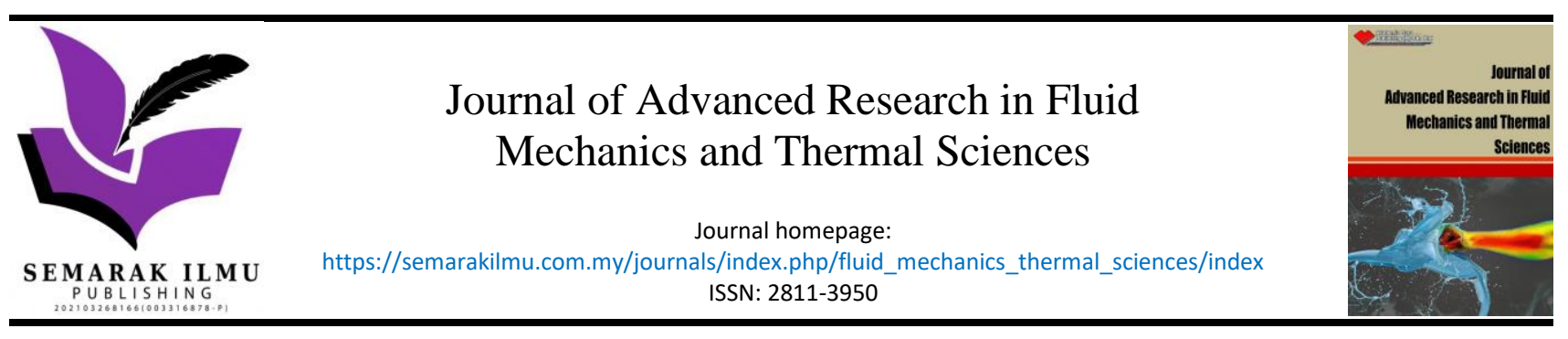

\title{
Numerical Analysis of the Effect of Temperature on the Pressure and Film Thickness for Line Contact Elastohydrodynamic Lubrication Using Bio- Based Oils as Lubricants
}

\author{
Dedi Rosa Putra Cupu ${ }^{1,}$, Kahar Osman² \\ Department of Mechanical Engineering, Faculty of Engineering, Universitas Riau, 28293 Pekanbaru, Riau, Indonesia \\ Department of Mechanical Engineering, Fakulti Kejuruteraan Mekanikal, Universiti Teknologi Malaysia, 81310 Skudai, Johor, Malaysia
}

ARTICLE INFO

\section{Article history:}

Received 26 September 2021

Received in revised form 22 December 2021

Accepted 23 December 2021

Available online 1 February 2022

\section{Keywords:}

Elastohydrodynamic Lubrication; Thermal EHL; Bio-based Lubricants; Film Thickness

\section{ABSTRACT}

This paper develops a numerical model to study the effect of lubricant's temperature on generated pressure and film thickness formation for the line contact elastohydrodynamic lubrication (EHL) using some bio-based oils as lubricants. In this study, a contact between inner ring and cylindrical roller of rolling element bearing is modelled as the line contact of EHL. The Reynolds equation is simultaneously solved with elastic deformation equation and pressure-viscosity equation. This aims to calculate the pressure distributions and film thickness profiles with a range of seven vegetable oils as bio-based lubricants at the various temperature. Moreover, the minimum film thickness is investigated in more detail to show the effect of the lubricant's temperature. Obtained results show that palm oil has the highest of the minimum film thickness among other vegetable oils. However, all vegetable oils simulated in this study are suitable to replace mineral oil as lubricant for application of roller element bearing.

\section{Introduction}

Elastohydrodynamic lubrication is one of the hydrodynamic lubrications, which involving physical interaction between the contacting bodies and the liquid of lubricant causes these contacting surfaces will be deformed elastically and the changes of viscosity with pressure play fundamental roles. The contacting surfaces in many engineering applications, for example, roller element bearings, gears, cams, seals, etc., are non-conformal; therefore, the consequent contact areas are very small and the resultant pressures are greatly high [1]. Based on their solid contacted bodies, EHL generally consists of two types of problems, line contact problems and point contact problems. Contact between two spherical balls and contact between ball and flat surface are represented as point contact problems. Cylindrical roller bearing is represented as line contact problems. In the line contact type, the rolling and load zones are angularly centered and rolling zone is smaller than the load zone [2].

\footnotetext{
* Corresponding author.

E-mail address: dedi.cupu@lecturer.unri.ac.id
}

https://doi.org/10.37934/arfmts.92.1.90104 
The purposes of lubrication are to control friction and wear and also to provide smooth running and a satisfactory life for machine elements. It separates surfaces in relative motion by interposing a third body that has a low resistance to shear. These lubricants are usually made by blending base oil and a special chemical additive. The base oil can be a variety of different materials; most of them are liquids (such as mineral oils, water, synthetic oils), but they may be solids (such as polytetrafluoroethylene, or PTFE) for use in dry bearings, grease used in rolling-element bearings, or gases (such as air) for use in gas bearings. According to a 2007 Freedonia report, total lubricant demand in the whole world is expected to be about 41.8 million metric tons, or about 13 billion gallons, where Asia/Pacific region will be the fastest growth [3]. The world market is segmented by application area is Engine oils - 48\%, Process oils - 15.3\%, Hydraulic oils $-10.2 \%$, and all other $26.5 \%$.

The considerations of increasing world energy crisis and environmental issues, in some countries, several laws and regulations have been enacted to control the production, application, and disposal of lubricants. These regulations have been released to minimize health hazards and water hazards [4]. Because of these two reasons, there is a need to source out biodegradable lubricants with technical characteristics superior to those based on mineral oils. It is already in use as lubricants for applications of chainsaw bar lubricants, straight metalworking fluids, food-industry lubricants, biodegradable grease, hydraulic fluids, marine oils, and outboard engine lubricants. It is used also as oils for water and underground pumps, rail flange lubricants, shock absorber lubricants, tractor oils, agricultural equipment lubricants, elevator oils, mold release oils, two-stroke engine lubricants, cold forward extrusion and so on $[5,6]$.

Lubricants based on vegetable oils are renewable and possess high biodegradability, high viscosity index, and excellent coefficient of friction and higher wear rate, possess good boundary lubricant [5,7-11]. Research in considering real measuring or testing the physical properties and tribological behavior for vegetable oils as lubricants have been investigated by researchers. These experimental concepts take a long time and need to destruct materials. However, at this moment, researchers need the accurate results quickly, and therefore study about bio-based lubricants used in line contact of elastohydrodynamic lubrication must be conducted and then a new numerical concept should be developed for this problem.

In this work, the lubricant properties of vegetable oils are obtained from the experimental results conducted by some researchers [7,9,12]. All properties are tabulated in Table 1. All oils are classified into vegetable oils, in this work consists of palm oil, coconut oil, camellia oil, olive oil and mustard oil; synthetic oil that represented by glycerol and mineral oil of P150 and paraffinic (PBSN). It is clearly seen that all vegetable oils have a wide range of kinematic viscosity at the two temperatures of $40^{\circ} \mathrm{C}$ and $100^{\circ} \mathrm{C}$. The viscosity of lubricant should be high enough to provide a continuous oil film, but not too high to avoid the friction between the two contacted bodies. It means that there is a range of kinematic viscosity should be considered before using the oil as the lubricant. According to Bannister [13], the required minimum kinematic viscosity for roller element bearing application at $40^{\circ} \mathrm{C}$ is 13 Centistokes, and the maximum is $1000 \mathrm{cSt}$. All vegetable oils in Table 1 have the kinematic viscosity between 25 to 250 Centistokes; these are feasible to be applied in roller element bearing.

Looking to viscosity classifications of engine oils, released by SAE (Society of Automotive Engineers), the kinematic viscosities of some vegetable oils at $100^{\circ} \mathrm{C}$ are ranging in $5.6-9.3 \mathrm{cSt}$ (SAE 20) [14]. The oils including Coconut oil, Canola oil, Olive oil, Camellia oil, Soybean oil and Sunflower oil. Mustard oil, with the kinematic viscosity at $100^{\circ} \mathrm{C}$ is $9.4 \mathrm{cSt}$, meets the grade of SAE 30 while Castor oil, the highest kinematic viscosity of $17.5 \mathrm{cSt}$ at $100^{\circ} \mathrm{C}$, is in range of SAE 50 . Another reason why these vegetable oils are chosen as the lubricants in this work is the values of their viscosity index (VI) are in range between 75 and 200. This range is represented for many industrial lubricating oils, 
for instance, automobile, gear, automatic transmission, turbine light, hydraulic fluids light and so on [15].

Friction is inevitable during the contact between components of rolling element bearing and lubricant. This causes heat generation in the lubricant especially at high speed and/or load operating conditions. Furthermore, the viscosity of vegetable oils significantly drops at high temperature as seen in Table 1. Therefore, temperature effects should be considered in analyzing the EHL cases with regarding to using bio-based lubricants for both line and point contact problems.

Table 1

Lubricant properties of tested oils

\begin{tabular}{llllll}
\hline Lubricants & \multicolumn{2}{c}{$\mathrm{mm}^{2} / \mathrm{s}$} & $\begin{array}{l}\rho, \mathrm{g} / \mathrm{mL} \\
10^{\circ} \mathrm{C}\end{array}$ & $\alpha, \mathrm{GPa}^{-1}$ & $\mathrm{G}$ \\
\hline Rapeseed oil & $40^{\circ} \mathrm{C}$ & $100^{\circ} \mathrm{C}$ & & \\
Palm oil & 35.7 & 8.06 & 0.9189 & 9.0 & 2075 \\
Coconut oil & 40.2 & 7.9 & 0.8930 & 17.13 & 3950 \\
Camellia oil & 27.6 & 5.9 & 0.9260 & 13.09 & 3020 \\
Olive oil & 39.3 & 8.3 & 0.9168 & 7.0 & 1615 \\
Mustard oil & 39.6 & 8.2 & 0.9137 & 8.1 & 1900 \\
Glycerol & 44.1 & 9.4 & 0.9180 & 9.46 & 2180 \\
Mineral Oil (P150N) & 209.3 & 12.0 & 1.2631 & 3.7 & 850 \\
PBSN & 28.6 & 5.1 & 0.8663 & 12.7 & 2930 \\
\hline
\end{tabular}

\section{Physical and Mathematical Formulation}

This section explains the general numerical procedure to solve the line contact of thermal elastohydrodynamic lubrication. The contact of the cylindrical roller element and inner ring of cylindrical rolling bearing is modeled as a contact between cylindrical roller and a plane under an external load, as seen in Figure 1. Both contacting bodies are elastic and are fully separated by a lubricant film. First, the numerical approach used in solving the isothermal EHL line contact problem is similar to that used by Houpert and Hamrock [1]. In this stage, the lubricant properties of vegetable oils, such as viscosity and pressure-viscosity coefficient at temperature of $40^{\circ} \mathrm{C}$ and density at $15^{\circ} \mathrm{C}$ as tabulated in Table 1, were used in the isothermal simulation. Then, in order to show the effect of lubricant's temperature on the film thickness and generated pressure distribution, the simulation code was running at different temperatures between $0^{\circ} \mathrm{C}$ and $100^{\circ} \mathrm{C}$ with all vegetable oils. Physical parameters involved in this simulation was tabulated in Table 2.

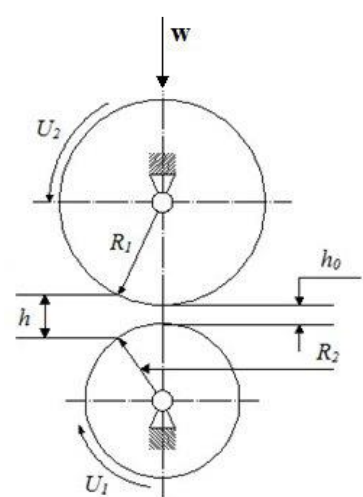

(a)

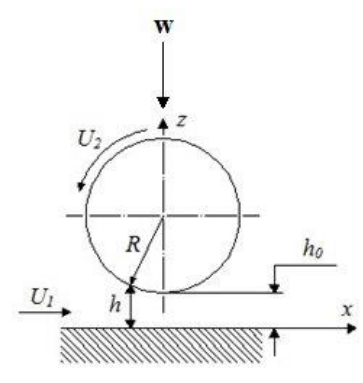

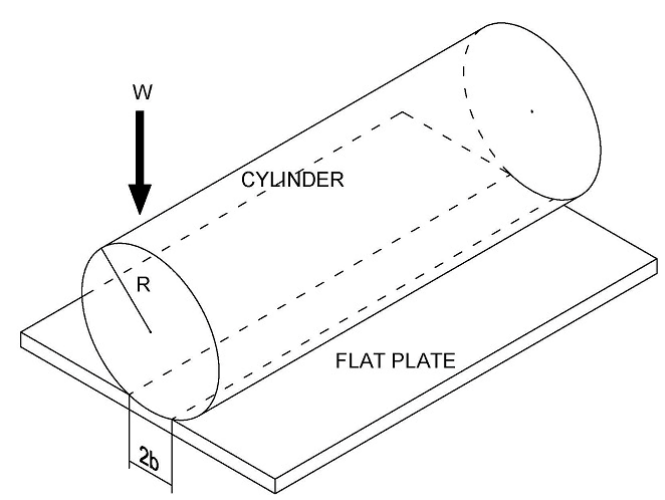

(b)

Fig. 1. (a) Simplification of the contact between roller bearing and inner or outer ring of cylindrical rolling element bearing and (b) the contact model of cylindrical roller and flat plate with external force 


\section{Table 2}

Physical parameters involved in this work

\begin{tabular}{ll}
\hline Parameters & Value \\
\hline Material of roller and ring & Steel AISI 52100 \\
Elastic Modulus $\left(E_{b}, E_{d}\right)$ & $210 \mathrm{GPa}$ \\
Poisson's ratio $\left(v_{a}, v_{b}\right)$ & 0.3 \\
Effective ball radius $(R)$ & $11.4 \mathrm{~mm}$ \\
Dimensionless applied load $(W)$ & $2.0452 \times 10^{-5}$ \\
Dimensionless speed $(U)$ & $1.0 \times 10^{-11}$ \\
Lubricant absolute viscosity $\eta_{0}$ & $6.6 \mathrm{~Pa} . \mathrm{s}$ \\
\hline
\end{tabular}

\section{Governing Equations}

The generalized Reynolds equation for a steady state condition of a line contact EHL problem derived by Dowson [16] and simplified as follows [17]:

$\frac{\partial}{\partial x}\left(\frac{h^{3}}{\eta} \frac{\partial p}{\partial x}\right)=12 u \frac{\partial h}{\partial x}$

where $u$ is the entrainment speed, $u=\left(u_{a}+u_{b}\right) / 2$

Letting the dimensionless parameters of below:

$W=\frac{w}{E^{\prime} R} ; H=\frac{h R}{b^{2}} ; U=\frac{\eta_{0} u}{E^{\prime} R} ; G=\alpha E^{\prime} ; X=\frac{x}{b} ; P=\frac{p}{p_{H}} ; \bar{\eta}=\frac{\eta}{\eta_{0}} ; \bar{\rho}=\frac{\rho}{\rho_{0}}$

where $p_{H}$ and $b$ are Hertzian dry contact parameters as follows [18]:

$b=\sqrt{\frac{8 w R}{\pi E^{\prime}}} ; p_{H}=\frac{2 w}{\pi b}=\sqrt{\frac{w E^{\prime}}{2 \pi R}}$

$R$ is the equivalent radius of roller bearing and $E^{\prime}$ is the effective elastic modulus can be calculated as [19]:

$\frac{1}{R}=\frac{1}{R_{a}}+\frac{1}{R_{b}} ; E^{\prime}=\frac{2}{\frac{1-v_{a}^{2}}{E_{a}}+\frac{1-v_{b}^{2}}{E_{b}}}$

where subscripts $a$ and $b$ mean the solid surface of 1 and 2 .

The dimensionless Reynolds equation becomes:

$\frac{\partial}{\partial X}\left(\varepsilon \frac{\partial P}{\partial X}\right)=\frac{\partial H}{\partial X}$

where

$\varepsilon=\frac{H^{3}}{\bar{\eta}} \frac{p_{H} b}{12 \eta_{0} u}$

The boundary conditions to solve the Reynolds equation are: 
$X=X_{\text {in }}, P=0$
$X=X_{\text {out }}, P=\frac{\partial P}{\partial X}=0$

The dimensionless film shape of the line contact EHL problem can be written as:

$H_{i}=H_{0}+\frac{X_{i}}{2}+\bar{\delta}_{i}$

where

$H_{0}=$ integration constant

$X_{i} / 2$ = separation due to geometry of the undeformed solids

$\bar{\delta}_{i}=$ dimensionless elastic deformation

Houpert and Hamrock [1] proposed a formula of elastic deformation to calculate the film thickness as follows:

$\bar{\delta}=-\frac{1}{2 \pi} \int_{X_{\min }}^{X_{\text {end }}} P \ln \left(X-X^{\prime}\right)^{2} d X^{\prime}-\frac{1}{4} \ln \left(R^{2} \frac{8 W}{\pi}\right)$

where the dimensionless applied load is:

$\int P d X^{\prime}=\frac{\pi}{2}$

For the isothermal condition, viscosity and density were assumed to depend on the pressure. Viscosity-pressure formula proposed by Roelands [20] as well as the density-pressure formula of Dowson and Higginson [21] were employed in this paper. The Roelands' viscosity-pressure relation in dimensionless reads:

$\bar{\eta}_{i}=\exp \left\{\left[\ln \left(\eta_{0}\right)+9.67\right]\left(-1+\left(1+5.1 \times 10^{-9} p_{H} P_{i}\right)^{Z}\right)\right\}$

where

$Z=\frac{\alpha}{\left(\ln \left(\eta_{0}\right)+9.67\right)\left(5.1 \times 10^{-9}\right)}$

And the dimensionless density-pressure formula is:

$\bar{\rho}_{i}=1+\frac{0.6 \times 10^{-9} p_{H} P_{i}}{1+1.7 \times 10^{-9} p_{H} P_{i}}$

To investigate the effect of the temperature on the pressure and film thickness, kinematic viscosity of each vegetable oils is calculated at different temperature using viscosity-temperature relationship proposed by Khonsari and Booser [15] as follows:

$\log (\log (v+0.7))=A-B(\log (T))$

where $A$ and $B$ are the constants of oils, and $T$ is the absolute temperature (K). 
The densities of all vegetable oils at various temperatures are needed to get the value of absolute viscosity by multiplying it with the kinematic viscosity. This can be calculated by use of the following formula [15]:

$\rho_{t}=\rho_{15.6}[1-0.000063(T-15.6)]$

Pressure-viscosity coefficient $(\alpha)$ is determined from the following equation involving absolute viscosity $\left(\eta_{0}\right)$ and Roelands' pressure-viscosity index $(Z)$ as mentioned by Khonsari and Booser [15]:

$\alpha=Z\left[5.1 \times 10^{-9}\left(\ln \left(\eta_{0}\right)+9.67\right)\right]$

Pressure-viscosity index is calculated as follows:

$Z=\left[7.81\left(H_{40}-H_{100}\right)\right]^{1.5}\left(F_{40}\right)$

where

$$
\begin{aligned}
& H_{40}=\log \left(\log \left(\eta_{40}\right)+1.200\right) \\
& H_{100}=\log \left(\log \left(\eta_{100}\right)+1.200\right) \\
& F_{40}=\left(0.885-0.864 H_{40}\right)
\end{aligned}
$$

Using the above formulas, the lubricant properties of vegetable oils that were needed to run simulation at various temperatures can be calculated. Table 2 shows the lubricant properties of one of vegetable oils, which were simulated in this work. It is noted that the material parameter $(G)$ in this table was obtained by multiplying the equivalent elastic modulus $\left(E^{\prime}\right)$ and pressure-viscosity coefficient $(\alpha)$.

\section{Results and Discussion}

\subsection{Isothermal-Steady State EHL Results}

This section discusses the results of pressure profile and film thickness shape obtained from the isothermal condition of the EHL line contact problem using some vegetable oils as lubricant. The effects of temperature on the pressure and film thickness are discussed in the next sub section. Dimensionless speed and load were similar to those used by Houpert and Hamrock [1], which were $W=2.0452 \times 10^{-5}$ and $U=1.0 \times 10^{-11}$. In order to solve the Reynolds equation, which is a partial differential equation, Hertzian dry contact pressure was used as initial condition. Figure 2 to Figure 7 show the pressure distribution and film thickness shape using rapeseed oil, palm oil, coconut oil, camellia oil, olive oil and mustard oil as lubricant. For comparison purposes, the pressure and film thickness using mineral oils and synthetic oil are depicted in Figure 7 to Figure 9.

Figure 2 shows the dimensionless pressure profile and film thickness shape using palm oil as the lubricant of rolling element bearing application. The horizontal axis represents the dimensionless distance of the contact. From this figure, it can be seen that the EHL pressure generated in the contact increased from the inlet position and then decreased after reaching the maximum value. It should be noted that the maximum pressure was not exactly at the centre of the bearing due to the effect of rotational movement. At the end of the contact area, there was a second maximum pressure 
occurred namely pressure spike. This is in line with the theory of the study by Dowson and Higginson [21]. Figure 2(b) shows the film thickness shape is almost flat at the contact area of roller element bearing. However, there was a dimple shape at the outlet area. This dimple was caused by the effect of the pressure spike pushing the lubricant at the end of the contact. The phenomena of pressure spike almost exist for all vegetable oils, even though there was a small spike when using camellia oil as the lubricant compared to other vegetable oils. Looking to Table 1, camellia oil has the lowest pressure-viscosity coefficient ( $\alpha=7.0$ ) while palm oil has the highest one ( $\alpha=17.3$ ). Compared to the pressure spike occurred when using mineral oils and synthetic oil as the lubricant as shown in Figure 10 to Figure 12, it can be concluded that the pressure-viscosity coefficient of the lubricant plays an important role in occurring the pressure spike. The higher the pressure-viscosity coefficient of lubricant, the higher the pressure spike occurred.

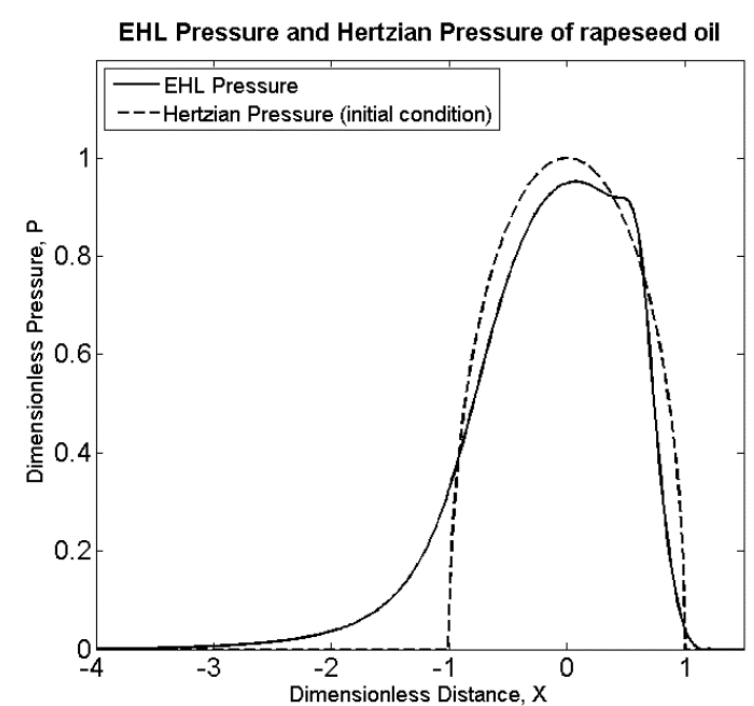

(a)

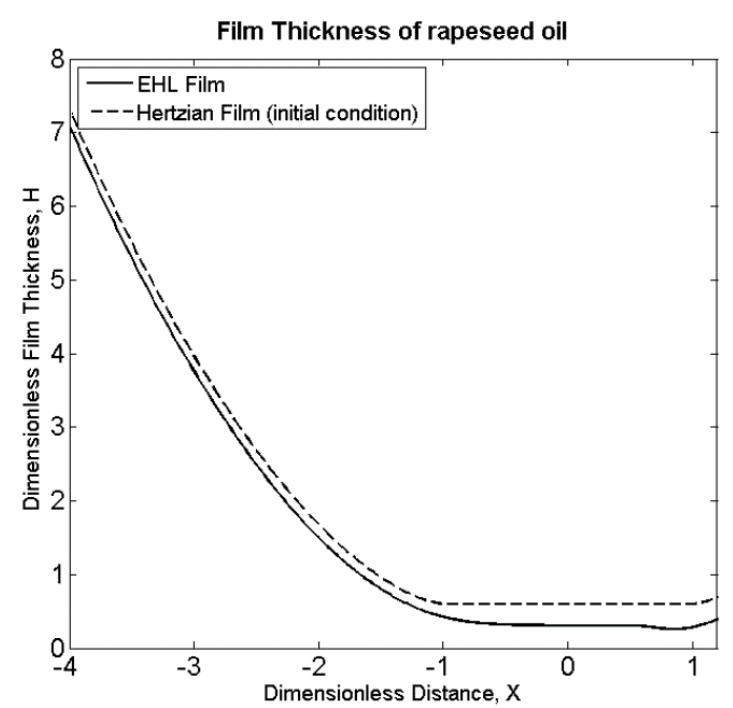

(b)

Fig. 2. EHL dimensionless pressure (a) and film thickness (b) using rapeseed oil as the lubricant

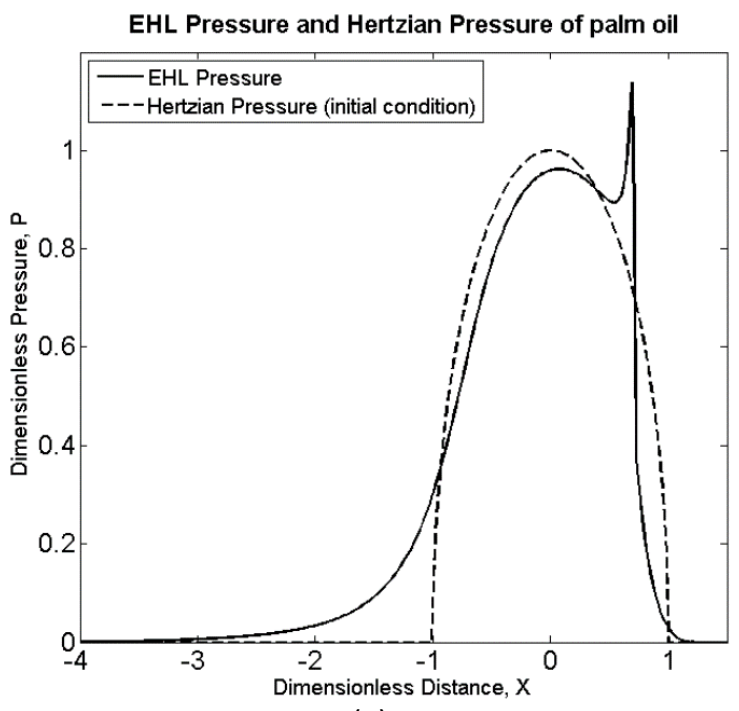

(a)

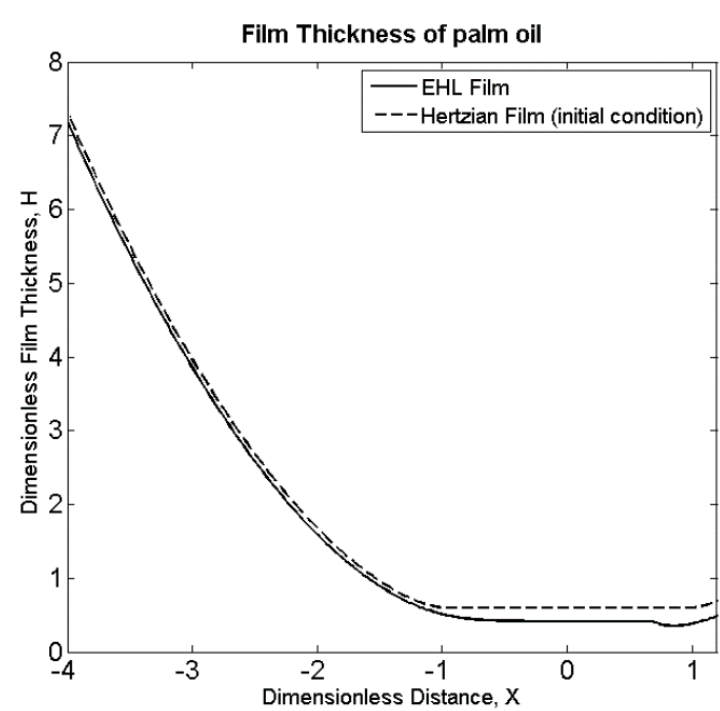

(b)

Fig. 3. EHL dimensionless pressure (a) and film thickness (b) using palm oil as the lubricant 


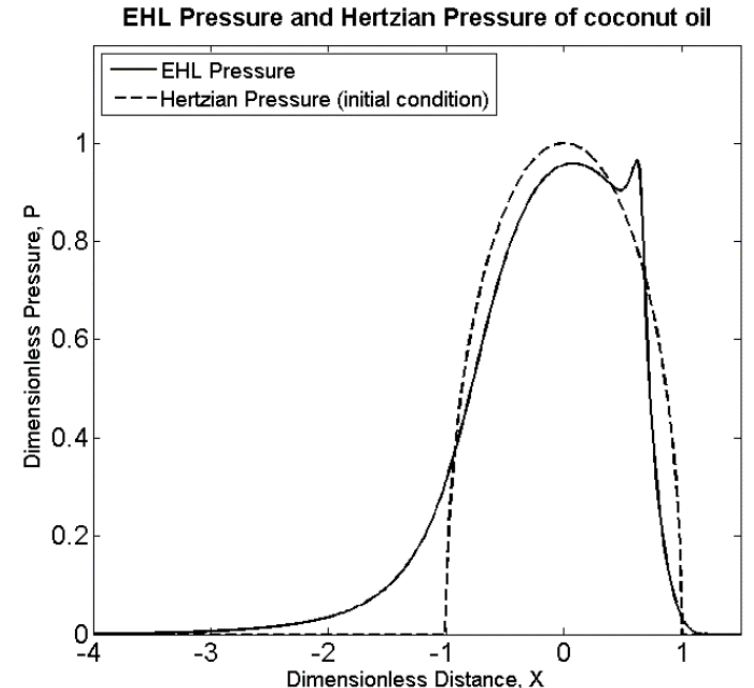

(a)

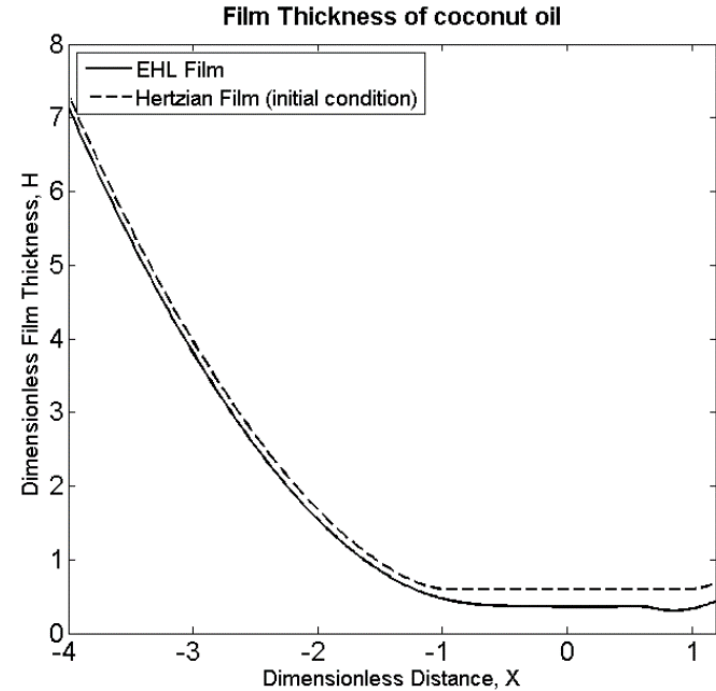

(b)

Fig. 4. EHL dimensionless pressure (a) and film thickness (b) using coconut oil as the lubricant

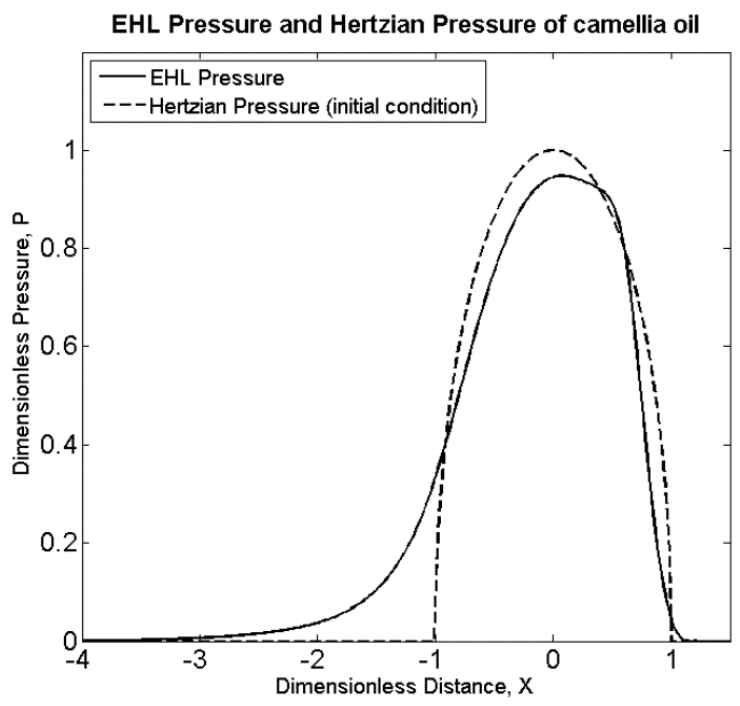

(a)

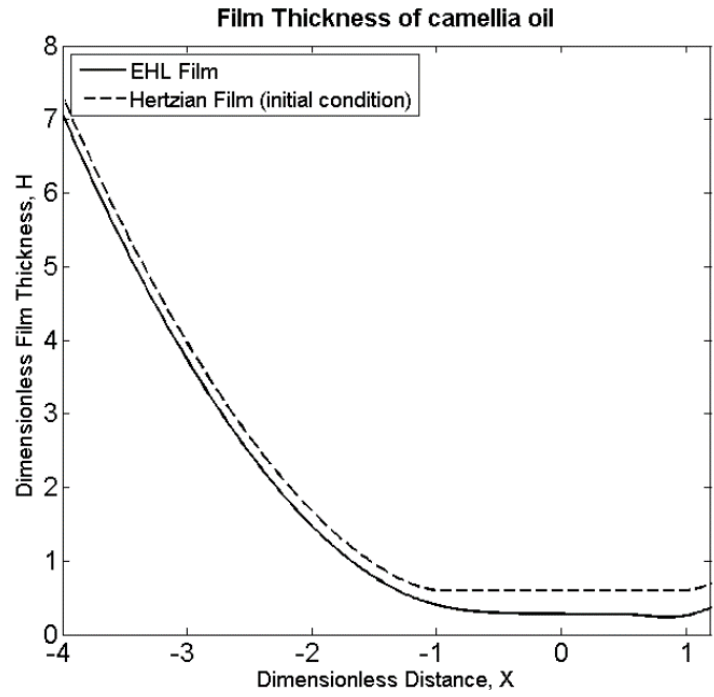

(b)

Fig. 5. EHL dimensionless pressure (a) and film thickness (b) using camelia oil as the lubricant

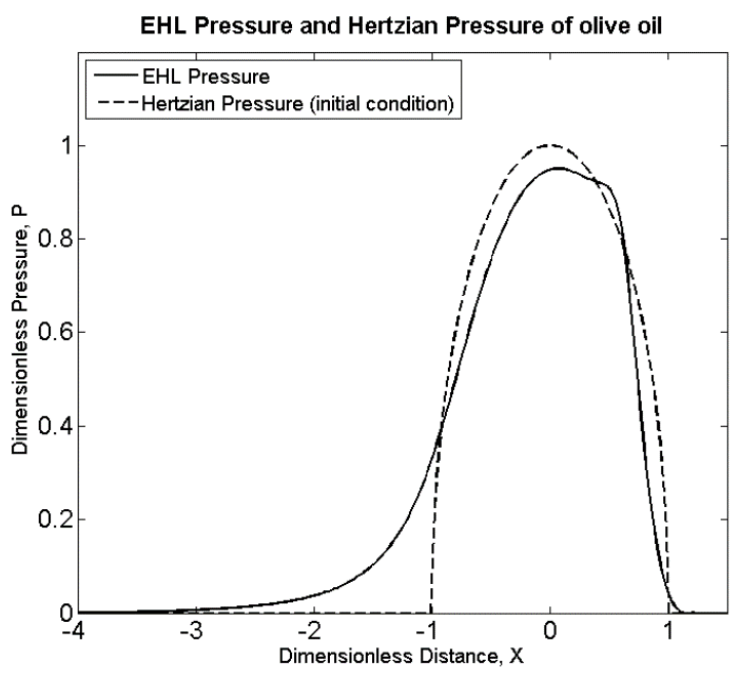

(a)

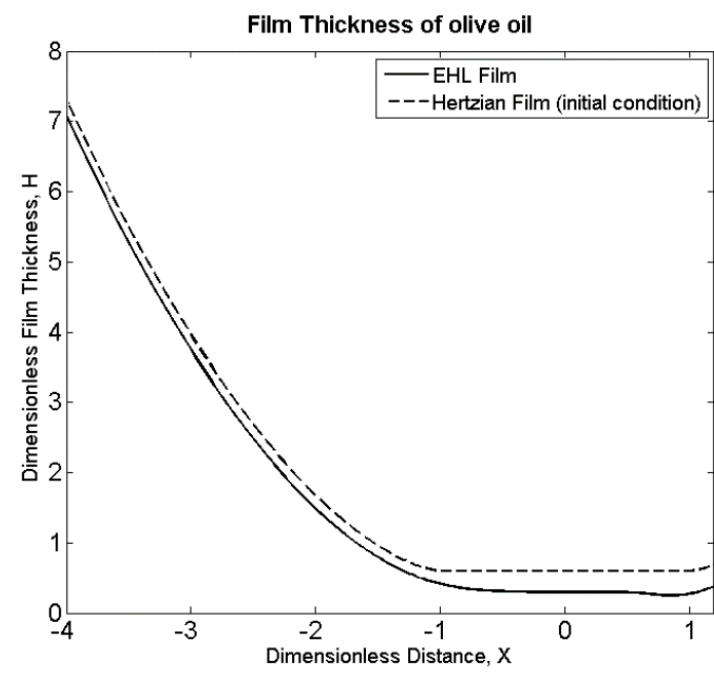

(b)

Fig. 6. EHL dimensionless pressure (a) and film thickness (b) using olive oil as the lubricant 


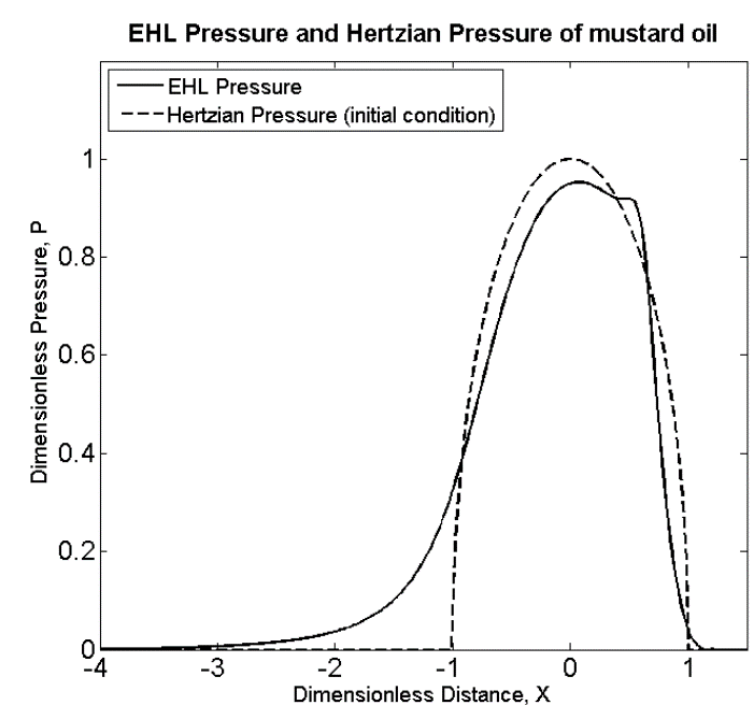

(a)

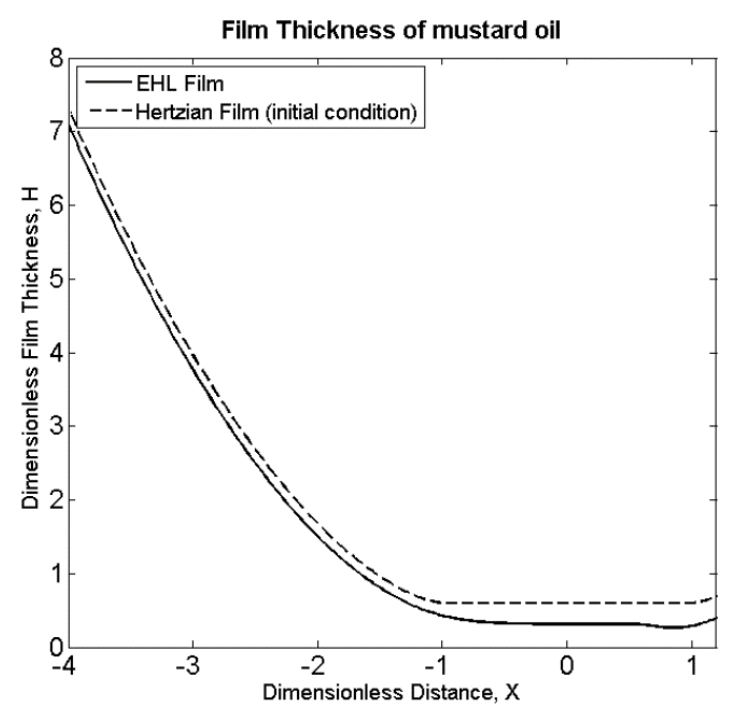

(b)

Fig. 7. EHL dimensionless pressure (a) and film thickness (b) using mustard oil as the lubricant

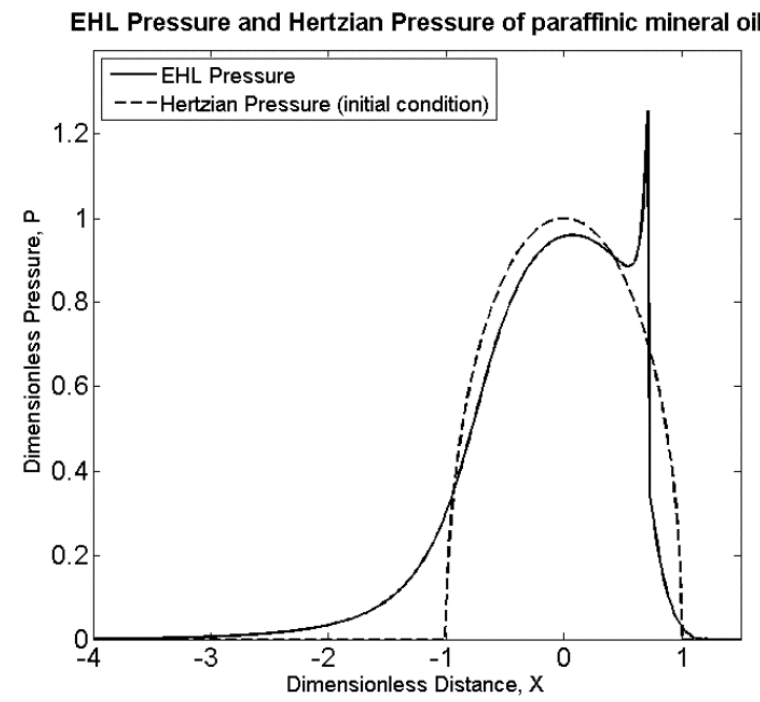

(a)

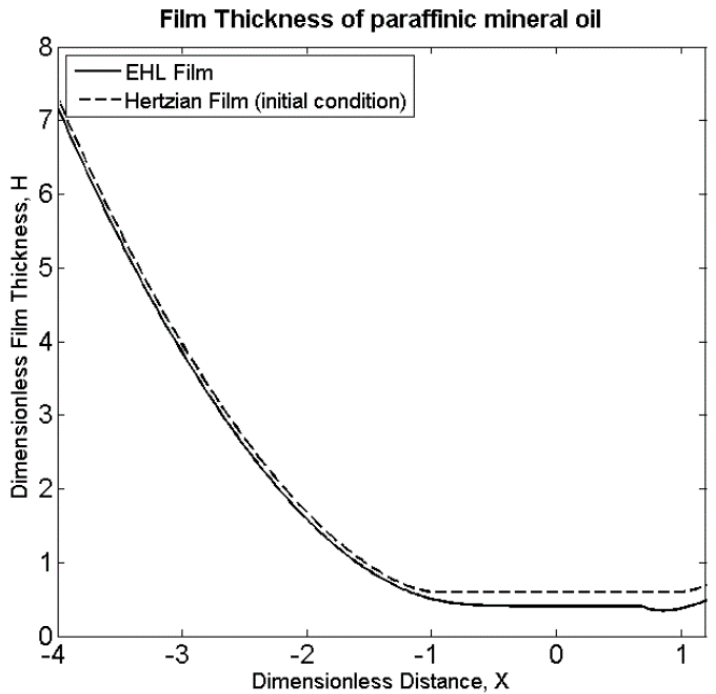

(b)

Fig. 8. EHL dimensionless pressure (a) and film thickness (b) using paraffinic mineral oil as the lubricant

In summary, the values of the maximum pressure and the minimum film thickness of all oils are tabulated in Table 3. Under isothermal condition, palm oil has the highest of the minimum film thickness among the other vegetable oils as well as the mineral and synthetic oils. In contrast, camellia oil has the lowest value of the minimum film thickness shape during simulation. The higher the minimum film thickness, the smaller the possibility of the solid bodies contacting each other. However, all vegetable oils simulated in this work are possible to replace the mineral oil and synthetic oil because they can form the film thickness between the contacting solids. 


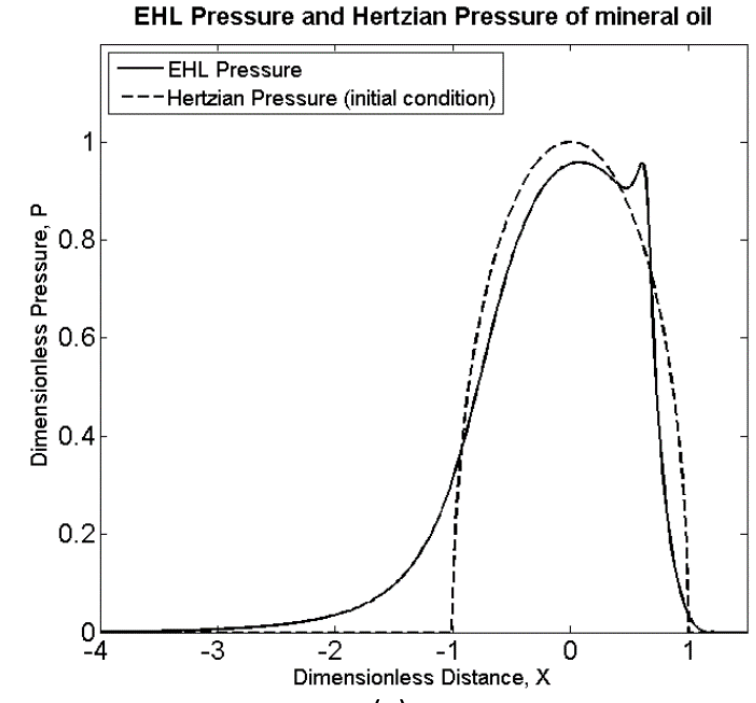

(a)

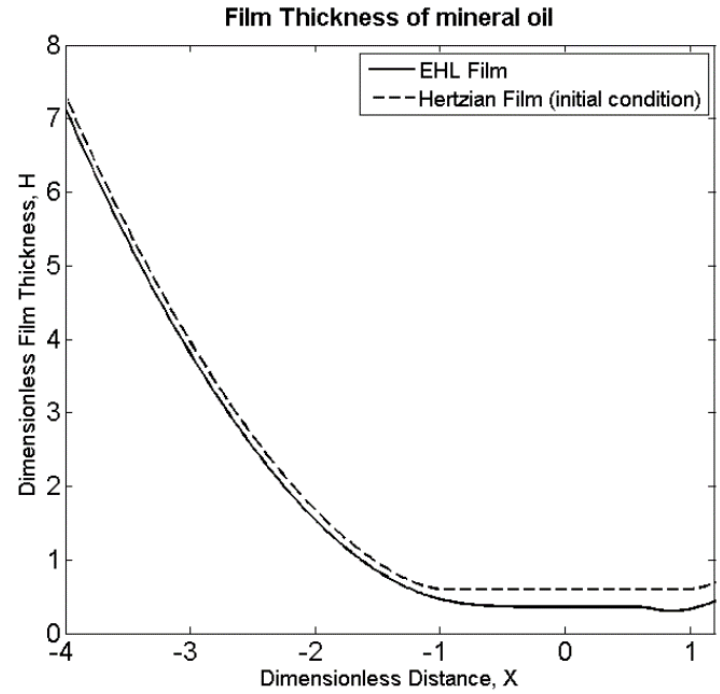

(b)

Fig. 9. EHL dimensionless pressure (a) and film thickness (b) using PBSN oil as the lubricant

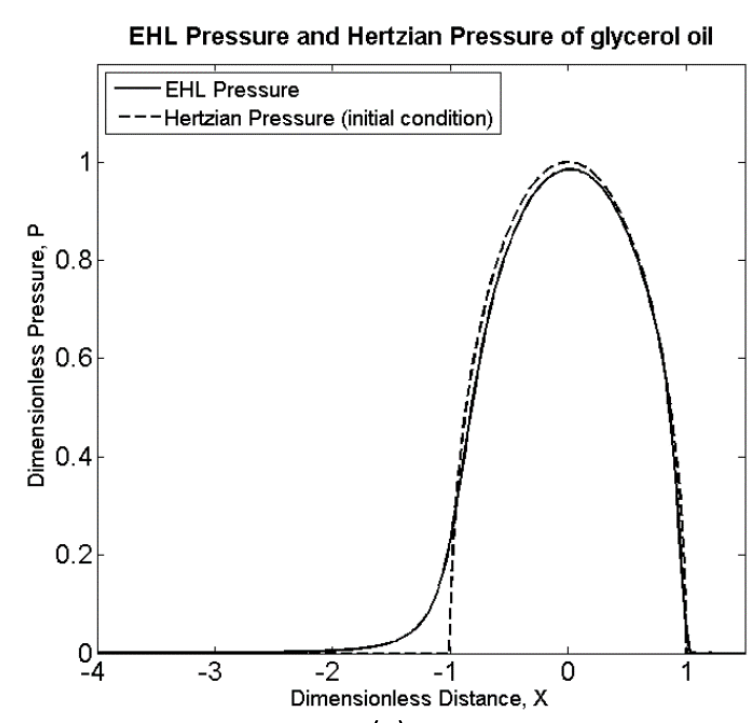

(a)

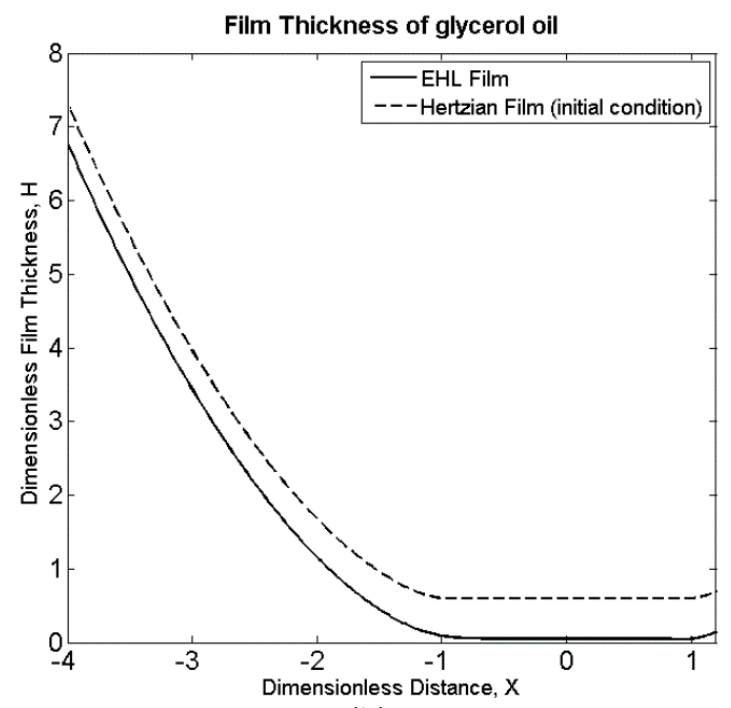

(b)

Fig. 10. EHL dimensionless pressure (a) and film thickness (b) using synthetic oil of glycerol as the lubricant

Table 3

Maximum pressure and minimum film thickness for all oils at temperature of $40^{\circ} \mathrm{C}$

\begin{tabular}{lll}
\hline Oils & Minimum film thickness, $h_{\min }(\mathrm{nm})$ & Maximum pressure, $p_{\max }(\mathrm{GPa})$ \\
\hline Palm oil & 56.173 & 0.474 \\
Coconut oil & 48.732 & 0.401 \\
Camellia oil & 37.121 & 0.395 \\
Olive oil & 39.540 & 0.396 \\
Mustard oil & 41.883 & 0.396 \\
For comparison purpose: & \\
Mineral oil & 48.013 & 0.394 \\
Glycerol & 30.435 & 0.390 \\
PBSN & 55.091 & 0.523 \\
\hline
\end{tabular}




\subsection{Temperature Effect on the Pressure and Film Thickness}

The effect of lubricant's temperature on the generated pressure and film thickness shape between the lubricated contacts of EHL line contact problem is studied in this sub section. Figure 11 and Figure 12 show the pressure and film thickness of EHL using rapeseed oil as the lubricant in various temperature between $0^{\circ} \mathrm{C}$ and $100^{\circ} \mathrm{C}$. The dimensionless applied load and speed were set fixed at $W=2.0452 \times 10^{-5}$ and $U=1.0 \times 10^{-11}$, respectively. In order to show the values of pressure and film thickness, the graphs shown in Figure 11 and Figure 12 were zoomed-in. Figure 11(b) shows the effect of temperature on the pressure maximum occurred at the centre of roller bearing. As an increase in the temperature of the lubricant, the value of kinematic viscosity decreased significantly and it caused the height of the pressure generated at the centre of roller become higher.

Looking to the trends of the pressure spike in the zoom-in of the dimensionless pressure distribution (Figure 11), it is clearly seen that the higher the temperature of lubricant the lower the pressure spike works at the contacted surfaces of component. Then, location of the pressure spike moved to the outlet region of roller bearing. This is confirmed with the theory of thermal elastohydrodynamic lubrication [22]. They stated that the increase of sliding ratio caused the increase of lubricant's temperature and the increase of temperature decreased the film thickness and the magnitude of the pressure spike.

Figure 12 shows the effect of the lubricant's temperature on the EHL film thickness with rapeseed oil is used as the lubricant. At the lower temperature, the value of the film thickness formed is much higher $\left(h_{\min }=63.0131 \mathrm{~nm}\right)$. As increasing temperature of the lubricant, the value of minimum film thickness and central film thickness decreased, and the location of minimum film thickness shifted to the centre of roller. This can be explained because the value of the pressure-viscosity coefficient of $\alpha$ is reduced at higher temperature, and hence the film thickness is decreased. This result of the lubricant's temperature effect on the film thickness is in accordance with the EHL theory and the EHL experimental result $[21,23]$.

Based on the above explanation, it can be concluded that the effect of the lubricant's temperature should be counted when the lubricant is used for the application of roller element bearing. The important parameter should be checked is the pressure maximum generated at the centre of bearing, and the pressure spike at the outlet area. In the above case $\left(\mathrm{W}=2.0452 \times 10^{-5}\right.$; $\mathrm{U}$ $=1.0 \times 10^{-11}$, and rapeseed oil is used as the lubricant), the maximum value of the pressure occurred at the higher temperature $\left(100^{\circ} \mathrm{C}\right)$. However, this high pressure was still below the pressure maximum using the paraffinic mineral oil as compared to Table 3. It means that rapeseed oil can still be used at higher temperature, but there are other parameters should also be considered, such as the flash point of this oil, pour point and so on.

At the same time, even though the maximum pressure at the centre of bearing is low at the lower temperature, the pressure spike should also be considered. Here, at temperature of $\mathrm{T}=0^{\circ} \mathrm{C}$, the pressure spike generated was much higher. At the low working temperature area, it is suggested to heat rapeseed oil before using it as the lubricant. However, normal temperature of food industry machinery, where the roller element bearing is used, is in range $40^{\circ} \mathrm{C}$ to $80^{\circ} \mathrm{C}$. At this range temperature, the pressure spike generated is about 0.35 to $0.45 \mathrm{GPa}$. 

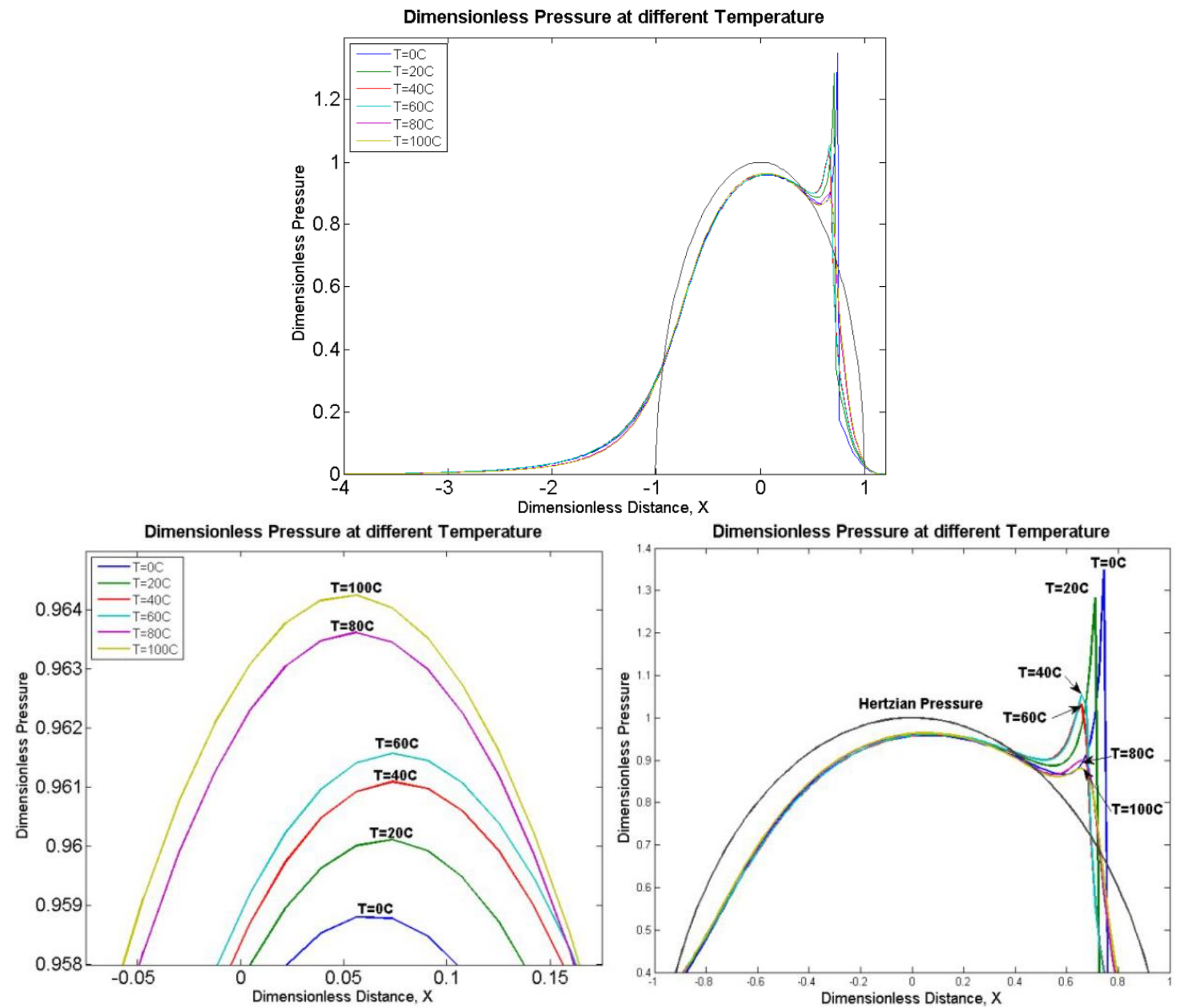

Fig. 11. Dimensionless pressure distribution for various lubricant's temperature using rapeseed oil as lubricant
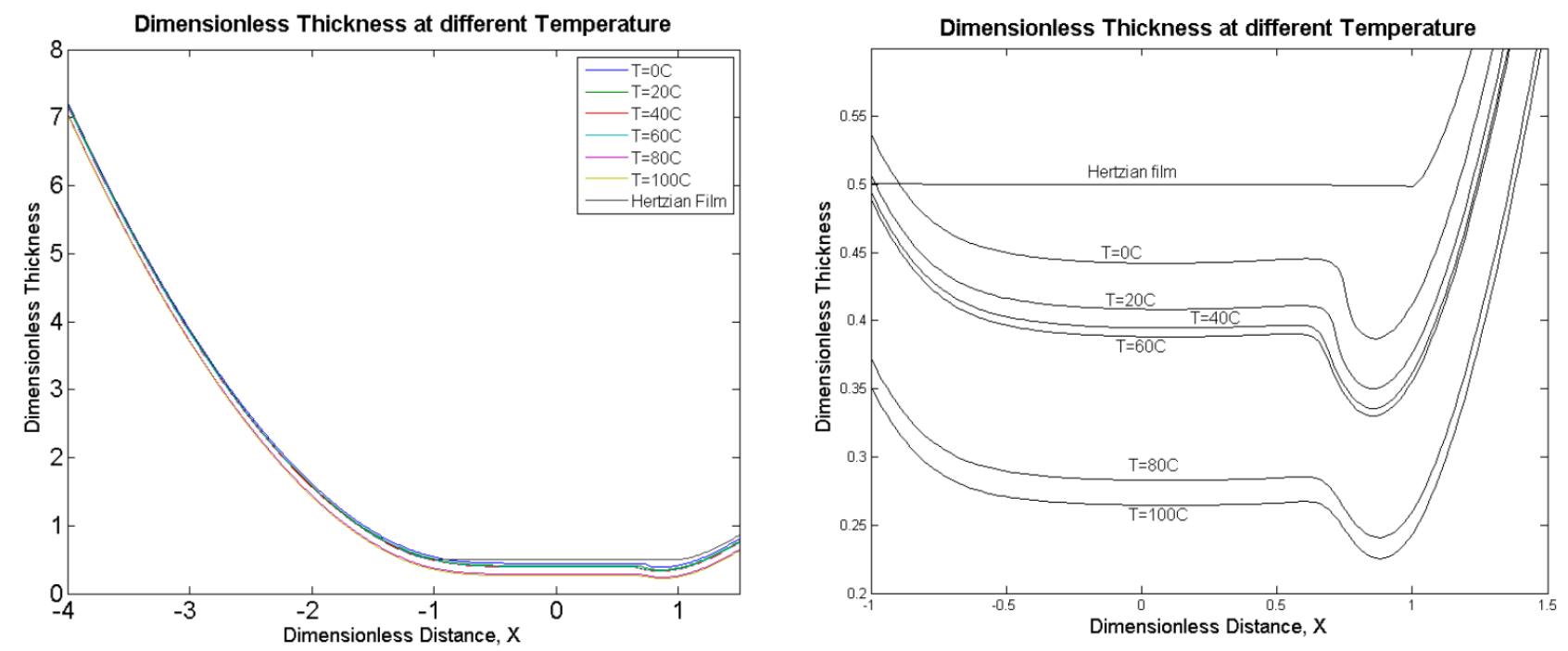

Fig. 12. Dimensionless film thickness shape for various lubricant's temperature using rapeseed oil as lubricant 
The effects of temperature on the characteristics of elastohydrodynamic lubrication using other vegetable oils are shown in Figure 13 and Figure 14. Then, the values of maximum pressure and film thickness are tabulated in Table 4 and Table 5 . It is noted that the solution could not converge for coconut oil at temperatures of $0^{\circ} \mathrm{C}$ and $20^{\circ} \mathrm{C}$. Then, changing the dimensionless speed to be $\mathrm{U}=1.0$ $\mathrm{x} 10^{-12}$, the numerical could be solved. It means that coconut oil is unsuitable for lubricant applying to the roller element bearing at the lower temperature of $40^{\circ} \mathrm{C}$.

From Figure 13 and Figure 14, it can be seen that the higher the lubricant's temperature the lower the maximum pressure generated in the contacting area and the thinner the minimum film thickness formed between the surfaces. However, the generated maximum pressure for all simulated vegetable oils at the higher lubricant's temperature of $80^{\circ} \mathrm{C}$ and $100^{\circ} \mathrm{C}$ were almost coincident between 0.39 and $0.40 \mathrm{GPa}$.

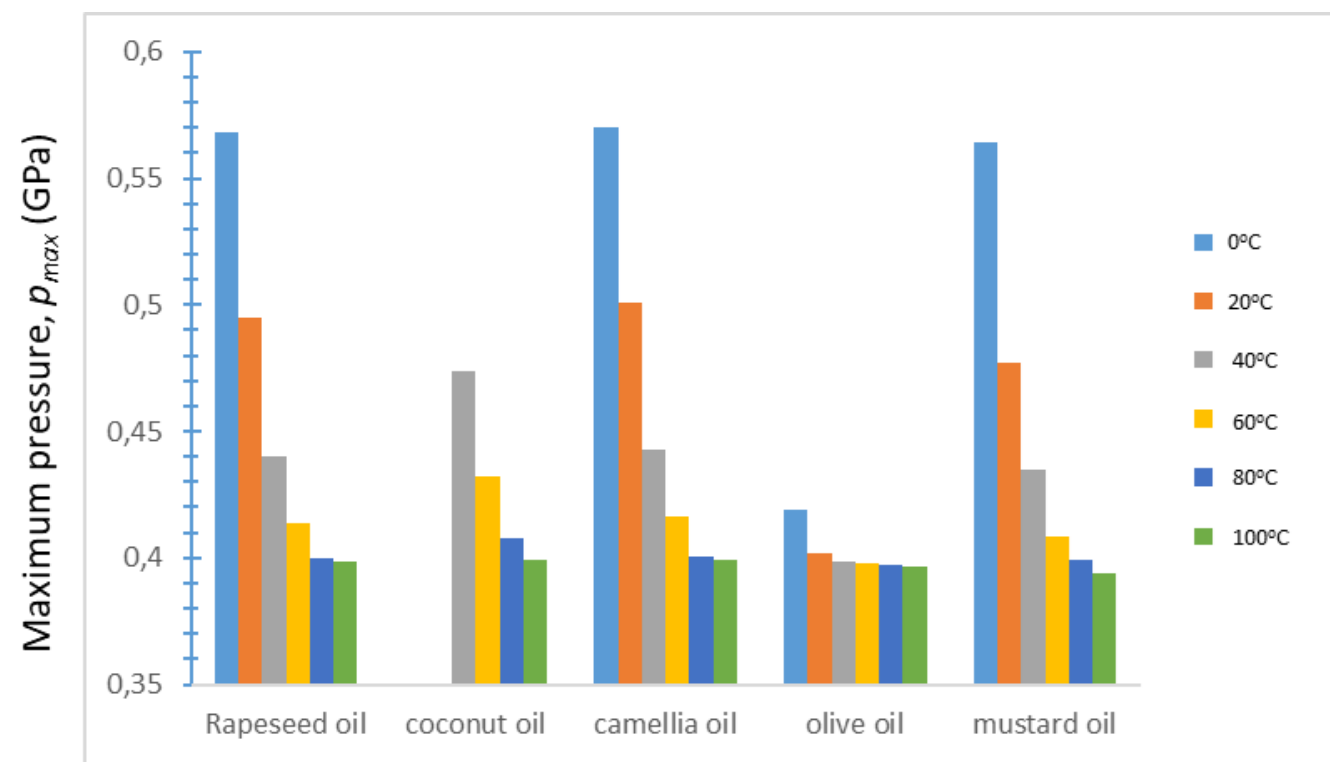

Fig. 13. Maximum pressure for different lubricant's temperature using five vegetable oils as lubricant

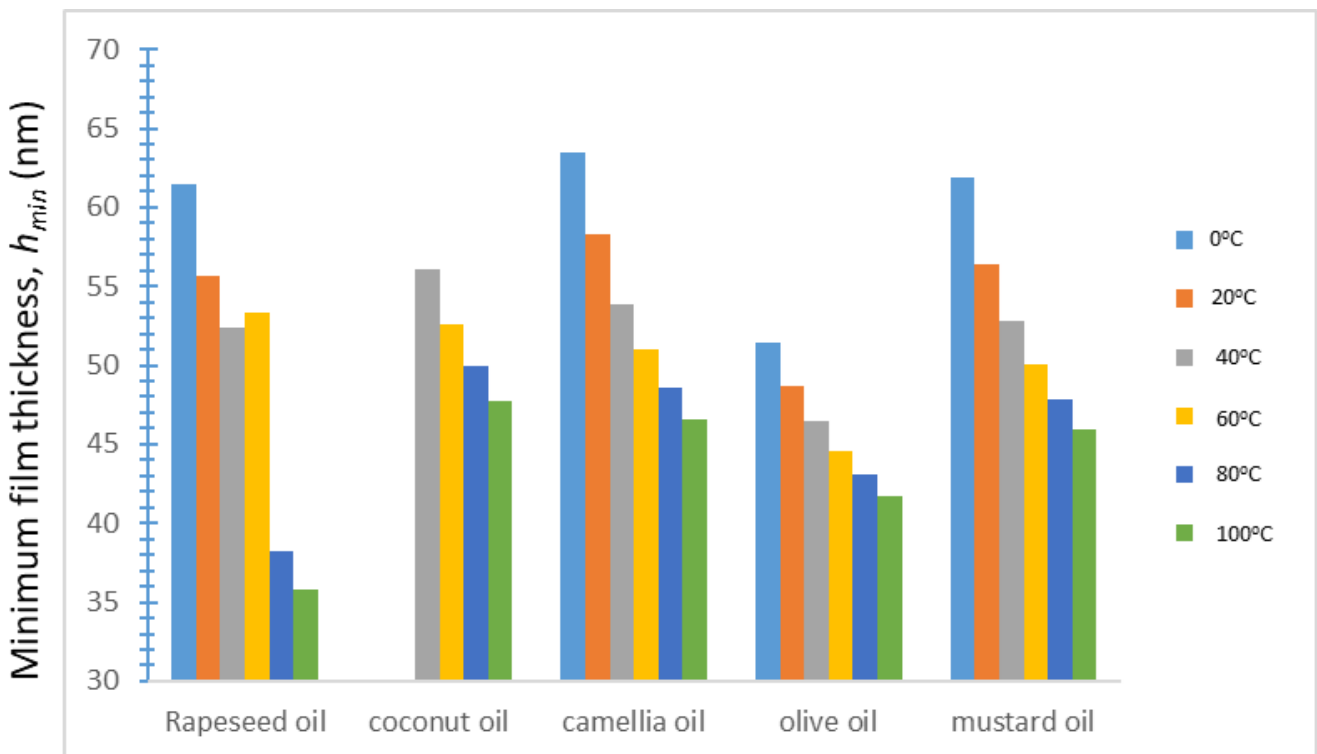

Fig. 14. Minimum film thickness for different lubricant's temperature using five vegetable oils as lubricant. 


\section{Table 4}

Maximum pressure of simulated vegetable oils running at various temperature $\left(W=2.0452 \times 10^{-5} ; U=\right.$ $1.0 \times 10^{-11}$ )

\begin{tabular}{llllll}
\hline Temperature $\left({ }^{\circ} \mathrm{C}\right)$ & \multicolumn{2}{l}{ Maximum pressure, $p_{\max }(\mathrm{GPa})$} & & \\
& Rapeseed oil & Coconut oil & Camellia oil & Olive oil & Mustard oil \\
\hline 0 & 0.5684 & NA & 0.5700 & 0.4191 & 0.5639 \\
20 & 0.4947 & NA & 0.5009 & 0.4016 & 0.4768 \\
40 & 0.4399 & 0.4740 & 0.4426 & 0.3985 & 0.4348 \\
60 & 0.4139 & 0.4324 & 0.4161 & 0.3979 & 0.4087 \\
80 & 0.3996 & 0.4081 & 0.4006 & 0.3974 & 0.3989 \\
100 & 0.3985 & 0.3989 & 0.3989 & 0.3968 & 0.3938 \\
\hline
\end{tabular}

\section{Table 5}

Minimum film thickness of simulated vegetable oils running at various temperature $(W=2.0452$ $\mathrm{x} 10^{-5} ; U=1.0 \times 10^{-11}$ )

\begin{tabular}{llllll}
\hline \multirow{2}{*}{ Temperature $\left({ }^{\circ} \mathrm{C}\right)$} & \multicolumn{4}{l}{ Minimum film thickness, $h_{\min }(\mathrm{nm})$} & \\
& Rapeseed oil & Coconut oil & Camellia oil & Olive oil & Mustard oil \\
\hline 0 & 61.4294 & NA & 63.4875 & 51.4549 & 61.9006 \\
20 & 55.6124 & NA & 58.2853 & 48.6958 & 56.4077 \\
40 & 52.4323 & 56.0789 & 53.8868 & 46.4560 & 52.8464 \\
60 & 53.3377 & 52.6240 & 50.9609 & 44.6023 & 50.0809 \\
80 & 38.2329 & 49.9507 & 48.5560 & 43.0377 & 47.8142 \\
100 & 35.7676 & 47.7443 & 46.5577 & 41.7113 & 45.9176 \\
\hline
\end{tabular}

\section{Conclusions}

The numerical simulations of EHL line contact problem using different vegetable oils have successfully been conducted under isothermal condition. The effect of lubricant's temperatures was also studied in this work by running the simulation code at six different temperatures between $0^{\circ} \mathrm{C}$ and $100^{\circ} \mathrm{C}$. The results show that all simulated vegetable oils are suitable to replace the mineral oil as the lubricant in the application of roller element bearing under isothermal condition. It was also observed that the lubricant's temperature caused the change of pressure distribution and pressure spike as well as the film thickness shape and the minimum film thickness between the contacting surfaces. The higher the lubricant's temperature, the lower the minimum film thickness formed in the contact. However, the change rate of the film thickness at the higher lubricant's temperature was lower than that of at the lower temperature.

\section{Acknowledgement}

This research was funded by a grant from Universitas Riau.

\section{References}

[1] Houpert, L. G., and Bernard J. Hamrock. "Fast approach for calculating film thicknesses and pressures in elastohydrodynamically lubricated contacts at high loads." Journal of Tribology 108, no. 3 (1986): 411-420. https://doi.org/10.1115/1.3261220

[2] Laniado-Jacome, Edwin, Jesús Meneses-Alonso, and Vicente Diaz-Lopez. "A study of sliding between rollers and races in a roller bearing with a numerical model for mechanical event simulations." Tribology International 43 , no. 11 (2010): 2175-2182. https://doi.org/10.1016/i.triboint.2010.06.014

[3] Bremmer, Bart J., and L. Plonsker. "Bio-based lubricants: a market opportunity study update." Omni-Tech International, Midland (2008).

[4] Bartz, Wilfried J. "Lubricants and the environment." Tribology International 31, no. 1-3 (1998): $35-47$. https://doi.org/10.1016/S0301-679X(98)00006-1 
[5] Erhan, Sevim Z., and Svajus Asadauskas. "Lubricant basestocks from vegetable oils." Industrial Crops and Products 11, no. 2-3 (2000): 277-282. https://doi.org/10.1016/S0926-6690(99)00061-8

[6] Syahrullail, S., B. M. Zubil, C. S. N. Azwadi, and M. J. M. Ridzuan. "Experimental evaluation of palm oil as lubricant in cold forward extrusion process." International Journal of Mechanical Sciences 53, no. 7 (2011): 549-555. https://doi.org/10.1016/j.ijmecsci.2011.05.002

[7] Adhvaryu, A., and S. Z. Erhan. "Epoxidized soybean oil as a potential source of high-temperature lubricants." Industrial Crops and Products 15, no. 3 (2002): 247-254. https://doi.org/10.1016/S0926-6690(01)00120-0

[8] Jayadas, N. H., K. Prabhakaran Nair, and G. Ajithkumar. "Tribological evaluation of coconut oil as an environmentfriendly lubricant." Tribology International 40, no. 2 (2007): $350-354$. https://doi.org/10.1016/i.triboint.2005.09.021

[9] Mia, Sobahan, Shinichiro Hayashi, and Nobuyoshi Ohno. "High pressure tribological behavior of vegetable oils as lubricant." In Proceedings of the International Conference on Mechanical Engineering, pp. 29-31. 2007.

[10] Musa, John J. "Evaluation of the Lubricating Properties of Palm Kernel Oil." Leonardo Electronic Journal of Practices and Technologies 7, no. 14 (2009): 107-114.

[11] Mia, Sobahan, and Nobuyoshi Ohno. "GE06 prospect of mustard and coconut oil as environment friendly lubricant for Bangladesh." In Proceedings of International Conference on Environmental Aspects of Bangladesh (ICEAB 10), University of Kitakyushu, Kitakyushu, Japan, September. 2010.

[12] Ohno, N., A. Shiratake, N. Kuwano, and F. Hirano. "Behavior of some vegetable oils in EHL contacts." In Tribology Series, vol. 32, pp. 243-251. Elsevier, 1997. https://doi.org/10.1016/S0167-8922(08)70453-X

[13] Bannister, Kenneth E. Lubrication for industry. Industrial Press Inc., 1996.

[14] Stachowiak, Gwidon W., and Andrew W. Batchelor. Engineering tribology. Butterworth-heinemann, 2005.

[15] Khonsari, Michael M., and E. Richard Booser. Applied tribology: bearing design and lubrication. John Wiley \& Sons, 2008. https://doi.org/10.1002/9780470059456

[16] Dowson, D. "A generalized Reynolds equation for fluid-film lubrication." International Journal of Mechanical Sciences 4, no. 2 (1962): 159-170. https://doi.org/10.1016/S0020-7403(62)80038-1

[17] Cupu, Dedi Rosa Putra, Adli Bahari, Kahar Osman, and Jamaluddin Md Sheriff. "Numerical Analysis of Elastohydrodynamic Lubrication with Non-Newtonian Lubricant." In Applied Mechanics and Materials, vol. 388, pp. 3-7. Trans Tech Publications Ltd, 2013. https://doi.org/10.4028/www.scientific.net/AMM.388.3

[18] Hertz, Heinrich. "On the contact of elastic solids." Z. Reine Angew. Mathematik 92 (1881): $156-171$. https://doi.org/10.1515/9783112342404-004

[19] Ghosh, M. K., and B. J. Hamrock. "Thermal elastohydrodynamic lubrication of line contacts." ASLE Transactions 28, no. 2 (1985): 159-171. https://doi.org/10.1080/05698198508981608

[20] Roelands, Cornelis Julianus Adrianus. "Correlational aspects of the viscosity-temperature-pressure relationship of lubricating oils." PhD diss., Technische Hogeschool te Delt (1966).

[21] Dowson, Duncan, and Gordon Robert Higginson. Elastohydrodynamic Lubrication: The Fundamentals of Roller and Gear Lubrication. Pergamon Press, Oxford, 1966.

[22] Blahey, A. G., and G. E. Schneider. "Paper VII (iii) A numerical solution of the elastohydrodynamic lubrication of elliptical contacts with thermal effects." In Tribology Series, vol. 11, pp. 219-230. Elsevier, 1987. https://doi.org/10.1016/S0167-8922(08)70948-9

[23] Biresaw, Girma. "Elastohydrodynamic properties of seed oils." Journal of the American Oil Chemists' Society 83, no. 6 (2006): 559-566. https://doi.org/10.1007/s11746-006-1240-9 